\title{
Radiofrequency sacroplasty (RFS) for the treatment of osteoporotic insufficiency fractures
}

\author{
Reimer Andresen • Christopher Wilhelm Lüdtke • \\ Sebastian Radmer $\cdot$ Peter Kamusella • \\ Hans-Christof Schober
}

Received: 2 August 2014/Revised: 22 October 2014/Accepted: 22 October 2014/Published online: 31 October 2014

(C) The Author(s) 2014. This article is published with open access at Springerlink.com

\begin{abstract}
Introduction and objective In elderly patients with reduced bone quality, insufficiency fractures of the sacrum are relatively common and are typically accompanied by severe, disabling pain. The objective of this study was to evaluate the feasibility of cement augmentation by RFS, as well as to determine postinterventional leakages and present the patients' outcomes.

Material and method In 20 patients (18 women, 2 men) with an average age of 80.4 (65-92) years, a fracture of the sacrum was detected by CT and MRI. Clinically manifest osteoporosis with QCT values of below $50 \mathrm{mg} /$ $\mathrm{ml}$ was found in all patients. An initially performed conservative treatment over a period of 3 weeks did not achieve a satisfactory reduction in the severe, disabling pain. The cement augmentation was performed under CT guidance by means of RFS under intubation anaesthesia. A Jamshidi needle was advanced into the respective fracture zone in the sacrum from dorsal to ventral (short axis) or from lateral to medial transiliac (transiliac axis).
\end{abstract}

\footnotetext{
R. Andresen $(\varangle) \cdot$ C. W. Lüdtke · P. Kamusella Institute of Diagnostic and Interventional Radiology/ Neuroradiology, Westkuestenklinikum Heide, Academic Teaching Hospital of the Universities of Kiel, Luebeck and Hamburg, Heide, Esmarchstraße 50, 25746 Heide, Germany e-mail: randresen@wkk-hei.de

\section{S. Radmer}

Centre for Orthopaedics, Berlin, Germany

H.-C. Schober

Department of Internal Medicine I, Municipal Hospital Suedstadt Rostock, Academic Teaching Hospital of the University of Rostock, Rostock, Germany
}

After removing the inner needle, a flexible osteotome was inserted through the positioned hollow needle and used to extend the spongious space in the fracture zone and thus prepare a cavity for the cement filling. The highly viscous polymethyl methacrylate (PMMA) cement, activated by radiofrequency, was then inserted into the prepared fracture zone through a substituted screw cannula. Cement filling was performed discontinuously under instrumental guidance at $1.3 \mathrm{ml} / \mathrm{min}$ under CT guidance. Cement leakages were determined in CT images and conventional X-rays on the day after the intervention. Pain was documented on a visual analogue scale (VAS) on the day before the intervention, on the second day, and after 6 and 12 months after the intervention. Additionally occurring complications were recorded, and the patients were asked to state how satisfied they were after 12 months.

Results RFS was technically feasible in all patients. In the control CT scans and X-rays, sufficient cement distribution and interlocking with vital bone was found along the course of the fracture in the sacrum. 7.2 (4-9) $\mathrm{ml}$ of cement were inserted per fracture. Leakage could be ruled out. The mean pain score on the VAS was $8.8 \pm 1.2$ before the intervention, and a significant reduction in pain $(p<0.001)$ was seen on the second postoperative day, with an average value of $2.3 \pm 0.7$, which was stable at $2.2 \pm 1.3$ after 6 months and $2.1 \pm 1.1$ after 12 months. All of the patients could be fully re-mobilised and discharged back home. A high level of patient satisfaction was found after 12 months, with 18 of the 20 patients stating that they would undergo the intervention again. One patient died of a stroke, another of cancer over the course.

Conclusion As a minimally invasive procedure, RFS is an effective and safe method of treatment for rapid, significant and sustained pain reduction. 
Keywords Insufficiency fracture $\cdot$ Sacrum

Osteoporosis - Radiofrequency sacroplasty · Pain therapy · Cement augmentation $\cdot$ Cement leakage

\section{Introduction}

If elderly patients with osteoporosis experience sudden deep-seated low back pain, the possible presence of an insufficiency fracture in the sacrum should be considered as a differential diagnosis $[1,2]$. These fractures usually take a vertical course and are classified into a transalar (type 1), a transforaminal (type 2) and a central zone of the fracture course (type 3) [3, 4]. The fractures can occur unilaterally or bilaterally, whereby the latter may be connected by horizontal branches at the level of the first sacral vertebra. A type 1 fracture zone is found most commonly in the case of insufficiency fractures. This fracture course is often characterised by the most severe, disabling pain, localised in the lower lumbar spine and pelvic region, while neurological deficits are an exception [2].

Up to now, the standard therapy for sacral insufficiency fractures has been conservative treatment with bed rest and adjuvant analgesic therapy, followed by mobilisation on a walking frame or on forearm crutches with pain-adapted weight-bearing [5]. A problematical aspect of conservative therapy is the increased risk of complications such as deep vein thrombosis, consecutive pulmonary artery embolisms, pneumonia, decubitus ulcers, and depression, while the immobilisation also leads to increasing muscle and bone degeneration [6]. The development of a pseudarthrosis with persistent pain is an additional problem of the conservative approach [6]. Osteosynthesis is available as a surgical treatment option, using various different techniques. As a result of the strongly rarefied bone structure, stable conditions cannot always be achieved here. The established method is percutaneous, transiliac screw fixation [7]. As an alternative minimally invasive form of treatment, cement can be inserted via hollow needles, analogously to vertebroplasty [8]. Rapid and virtually complete pain reduction has been demonstrated with this new method, although leakages may occur as a complication and are not always free of symptoms [9, 10]. Sacroplasty with balloon dilatation, analogous to kyphoplasty, was first performed by Deen and Nottmeier [11] on three patients. The safe feasibility of CT-guided balloon sacroplasty was later confirmed in a cadaver study [12] and in various clinical studies [4, 13, 14]. For RFS, a case report [15] and initial investigations $[16,17]$ have also shown good results with regard to pain reduction.

The extent to which cement augmentation by RFS offers advantages in technical performance and safety and how the clinical outcome develops was investigated retrospectively on 20 patients over a postinterventional period of 12 months.

\section{Material and method}

We investigated 20 consecutive patients (18 women, 2 men) retrospectively with an average age of 80.4 (65-92) years, with a fracture of the sacrum detected by $\mathrm{CT}$ and MRI. The patients were treated between June 2011 and April 2013. The fractures were classified according to Denis et al. [3]. To estimate the extent of demineralisation of the axial skeleton, bone density was determined in all patients by means of quantitative computed tomography (QCT).

Conservative treatment initially performed over a period of 3 weeks did not bring any satisfactory reduction of the severe, disabling pain. The indication for intervention was established after an interdisciplinary case conference with specialists in geriatrics/internal medicine, orthopaedic/ trauma surgeons, neurosurgeons and interventional radiologists. The cement augmentation was performed with CTguidance by RFS under intubation anaesthesia and anaesthetic monitoring. Single-shot antibiotic prophylaxis was given routinely (cefazoline $2 \mathrm{~g}$ i.v.) immediately prior to the intervention. Under sterile conditions, a $10 \mathrm{G}$ Jamshidi needle was then advanced into the respective fracture zone in the sacrum from dorsal to ventral (short axis) or from lateral to medial transiliac (transiliac axis) (Fig. 1) [3]. After removing the inner needle, an $11.5 \mathrm{G}$ flexible midline osteotome was inserted through the positioned hollow needle and used to extend the spongious space in the fracture zone and thus prepare a cavity for the cement filling. The highly viscous polymethyl methacrylate (PMMA) cement (StabiliT ${ }^{\circledR}$ ER $^{2}$ Bone Cement made by DFine Europe $\mathrm{GmbH}$ ), activated by radiofrequency, was then inserted into the prepared fracture zone through a substituted screw cannula. Cement filling was performed discontinuously under instrumental guidance at $1.3 \mathrm{ml} / \mathrm{min}$ (StabiliT $^{\circledR}$ Vertebral Augmentation System-Radiofrequency Kyphoplasty by DFine Europe $\mathrm{GmbH}$ ) under CT guidance. Cement leakages were determined in $\mathrm{CT}$ images and conventional X-rays on the day after the intervention. Pain was documented on a visual analogue scale (VAS) on the day before the intervention, on the second day, and after 6 and 12 months after the intervention. Additionally occurring complications were recorded, and the patients were asked to state how satisfied they were in a standardised questionnaire after 12 months.

Patients with additional fractures in the pelvic ring were excluded from the study. 
Fig. 1 The fracture zones according to Denis et al. [3] are indicated on the left-hand side. The approaches used via the short and transiliac axis are shown on the right-hand side

\section{Fracture zones and approaches}

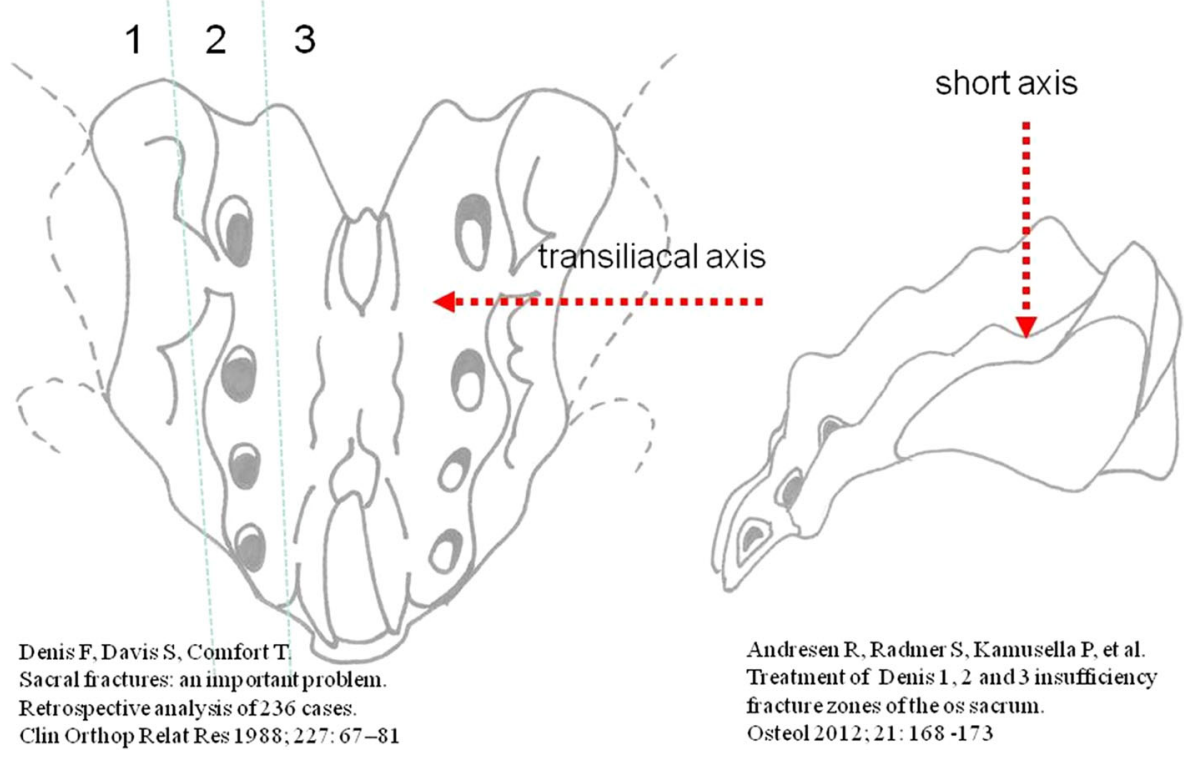

The results were tested for significance by means of rank variance analysis for several matched samples according to Friedman.

\section{Results}

With regard to fracture type, a bilateral Denis 1 was found six times, a bilateral Denis 1-2 twice, a unilateral Denis 1 seven times, and a unilateral Denis 1-2 fracture zone five times. A pure Denis 2 or Denis 3 fracture zone was not found.

A severe demineralisation with bone mineral content values markedly below $50 \mathrm{mg} / \mathrm{ml}$ was determined in all patients.

RFS was technically feasible in all patients. The cement was inserted exclusively using an approach via the short axis in the case of Denis 1 fracture zones, while an approach via the transiliac axis was used in a few of the cases with Denis 1-2 fracture zones. The calculated mean effective dose for the intervention was $4.0 \mathrm{mSv}$ (SD $0.8 \mathrm{mSv}$ ).

In the control CT scans and X-rays, sufficient cement distribution and interlocking with vital bone was found along the course of the fracture in the sacrum. An average of 7.2 (4-9) $\mathrm{ml}$ of cement was inserted per fracture. Leakage was ruled out in all cases (Figs. 2, 3). The mean pain score on the VAS was $8.8 \pm 1.2$ before the intervention, and a significant reduction in pain $(p<0.001)$ was seen on the second postoperative day, with an average value of $2.3 \pm 0.7$, which was stable at $2.2 \pm 1.3$ after
6 months and $2.1 \pm 1.1$ after 12 months (Fig. 4). Now that they no longer experienced disabling pain, the patients could be fully re-mobilised and discharged back home. The mean inpatient hospital stay after sacroplasty was 4 days. A high level of patient satisfaction was found after 12 months, with 18 of the 20 patients stating that they would undergo the intervention again. One patient died of a stroke, another of cancer over the course. No renewed fracture was detected in the 18 of 20 patients over the further course. Intervention-related infection, bleeding or increased mortality was not found.

\section{Discussion}

The conservative therapy of sacral insufficiency fractures with immobilisation and pharmacotherapy of pain and osteoporosis [18] leads to an increase in other comorbidities as a result of the immobilisation and often only brings clinical improvement in the long term [5, 19]. Since a rapid analgesic effect with a positive effect on mobility and the activities of daily living has been repeatedly shown after sacroplasty $[4,8,9,11,13,14]$, this therapeutic option should be taken after an unsuccessful attempt at conservative treatment with persistent disabling pain. Cement augmentation analogous to vertebroplasty [8-10] or balloon kyphoplasty $[4,9,11,13,14]$ come into question here. Greater clinical experience has been gained in cement insertion via a placed hollow needle in accordance with vertebroplasty, although higher rates of cement leakage are experienced here, as in the treatment of vertebral body 

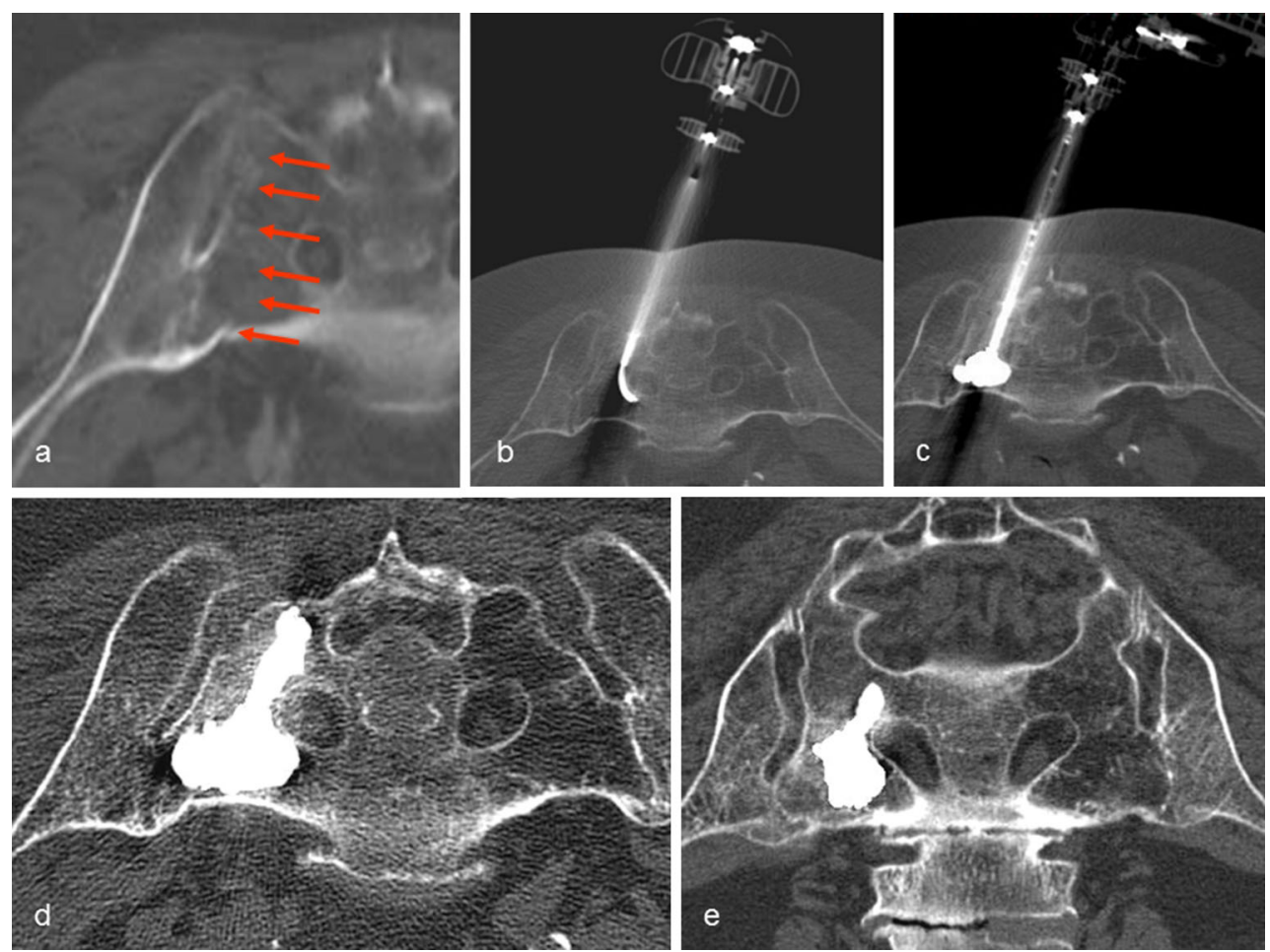

Fig. 2 a Axial CT image of a Denis 1 fracture zone of the sacrum on the right. b Preparation of the fracture zone with the flexible osteotome. c Instrumentally guided cement insertion. d In the axial

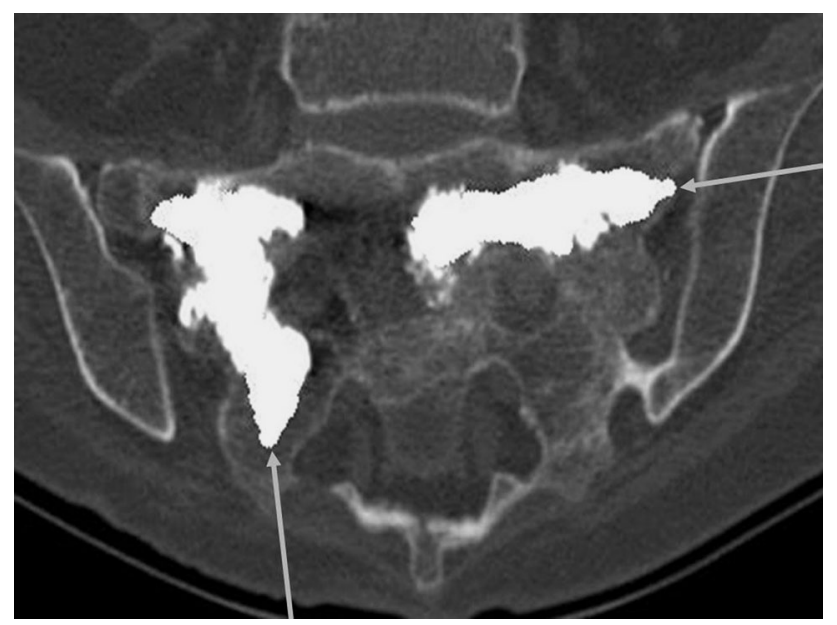

Fig. 3 Treatment of a Denis 1 fracture zone on the right and of a Denis 1 and 2 fracture zone on the left. The approach was via the short axis on the right and via the transiliac axis on the left. On both sides, a central cement plug can be seen in the fracture zone. A cement leakage in the direction of the neuroforamina, iliosacral joints or visceral surface of the sacrum can be ruled out

fractures $[9,10]$. A central cavity for insertion of the cement can be created using a balloon catheter, whereby a compaction of the surrounding fracture zone seals possible fracture fissures and thus minimises cement leakage [4, 12$14]$. On the basis of good clinical experience $[20,21]$ with
CT image and $\mathbf{e}$ in coronal reformation, presentation of the cement plug in the fracture zone. Taking into account both sectional planes, cement leakage can be ruled out

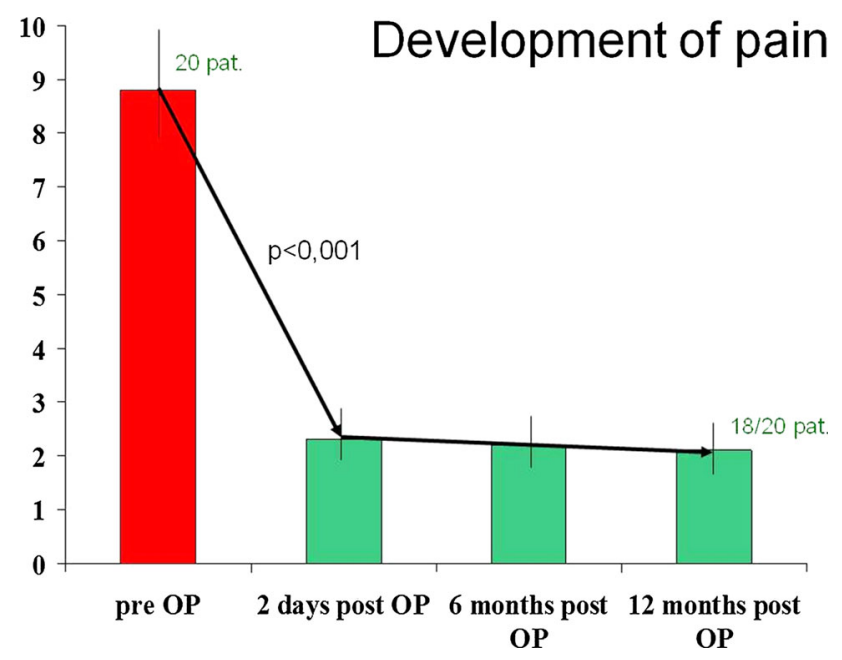

Fig. 4 Pain development before and after the RFS. Before the intervention, there was a high pain level of on average 8.8 score points. As early as the second postoperative day, a significant pain reduction to an average of 2.3 score points can be seen. This remained consistently stable over the further course, at 2.2 after 6 months and 2.1 after 12 months

regard to pain reduction, a low rate of leakage and vertebral body reconstruction with highly viscous cement insertion by means of radiofrequency kyphoplasty on the spine and initial good results after RFS with regard to pain reduction 
[15-17], we also treated 20 patients with osteoporotic insufficiency fractures of the sacrum by means of radiofrequency-guided cement insertion. As reported by Klingler et al. [16] and Eichler et al. [17], we also observed a significant pain reduction in all patients. Klingler et al. [16] found asymptomatic PMMA leakages in $100 \%$ of their cases and Eichler et al. in $5.5 \%$, in contrast to $0 \%$ in our study. The approaches selected were possibly disadvantageous, taking into account the complex anatomy of the sacrum, as the approach chosen in the two studies was via the long axis [22], whereas we chose an approach via the short or transiliac axis [23, 24]. A further advantage of the short and transiliac axis is the imaging of the entire needle of the application system in the axial CT image. Here, individual CT images can be examined during cement application to predict and prevent a leakage, whereby the possibility of interrupting hydraulic insertion of the highly viscous cement by remote control is a great advantage [25]. In our opinion, the procedure should be done under CT guidance due to the fact that under fluoroscopy the reduced bone structure, as usually found in osteoporotic patients, as well as the complex three-dimensional anatomy of the sacrum can not be reliably visualised. As a minimally invasive procedure, RFS is an effective, safe method of treatment for rapid, significant and sustained pain reduction. In the case of CT-guided RFS, the approaches via the short or transiliac axis appear to be the safest. Based on the available evidence RFS is an option to treat sacral fractures after failed conservative treatment.

\section{Conflict of interest None.}

Open Access This article is distributed under the terms of the Creative Commons Attribution License which permits any use, distribution, and reproduction in any medium, provided the original author(s) and the source are credited.

\section{References}

1. Dasgupta B, Shah N, Brown H et al (1998) Sacral insufficiency fractures: an unsuspected cause of low back pain. Br J Rheumatol 37(7):789-793

2. Schindler OS, Watura R, Cobby M (2007) Sacral insufficiency fractures. J Orthopaedic Surg 15(3):339-346

3. Denis F, Davis S, Comfort T (1988) Sacral fractures: an important problem. Retrospective analysis of 236 cases. Clin Orthop Relat Res 227:67-81

4. Andresen R, Radmer S, Kamusella P et al (2012) Treatment of Denis 1,2 and 3 insufficiency fracture zones of the os sacrum. Individual approaches adapted to the course of the fracture in CTassisted balloon sacroplasty. Osteol 21(3):168-173

5. Babayev M, Lachmann E, Nagler W (2000) The controversy surrounding sacral insufficiency fractures: to ambulate or not to ambulate? Am J Phys Med Rehabil 79(4):404-409

6. Lin JT, Lane JM (2003) Sacral stress fractures. J Womens Health 12(9):879-888
7. Routt ML Jr, Simonian PT (1996) Closed reduction and percutaneous skeletal fixation of sacral fractures. Clin Orthop Relat Res 329:121-128

8. Garant M (2002) Sacroplasty: a new treatment for sacral insufficiency fracture. J Vasc Interv Radiol 13(12):1265-1267

9. Lyders EM, Whitlow CT, Baker MD et al (2010) Imaging and treatment of sacral insufficiency fractures. AJNR Am J Neuroradiol 31(2):201-210

10. Bastian JD, Keel MJ, Heini PF et al (2012) Complications related to cement leakage in sacroplasty. Acta Orthop Belg 78(1): $100-105$

11. Deen HG, Nottmeier EW (2005) Balloon kyphoplasty for treatment of sacral insufficiency fractures. Report of three cases. Neurosurg Focus 18(3):1-5

12. Briem D, Grossterlinden L, Begemann PG et al (2008) CT-guided balloon-assisted sacroplasty. Preliminary results of a feasibility study. Unfallchirurg 111(6):381-386 (Article in German)

13. Andresen R, Radmer S, Kamusella $P$ et al (2012) Interventional pain relief using Balloon-Kyphoplasty in patients with osteoporotic-based fatigue fractures of the Os sacrum. Fortschr Röntgenstr 184(1):32-36 (Article in German)

14. Shah RV (2012) Sacral kyphoplasty for the treatment of painful sacral insufficiency fractures and metastases. Spine J 12(2):113120

15. Andresen R, Lüdtke CW, Kamusella P (2013) Radiofrequenzsakroplastie zur Versorgung einer einseitigen Denis 1 Insuffizienzfraktur. Osteoporose \& Rheuma aktuell 2:16-19 (Article in German)

16. Klingler JH, Kluge P, Sicar R et al (2013) First experience using navigation-guided radiofrequency kyphoplasty for sacroplasty in sacral insufficiency fractures. Fortschr Röntgenstr 185(8):733740

17. Eichler K, Zangos S, Mack MG et al (2014) Outcome of longaxis percutaneous sacroplasty for the treatment of sacral insufficiency fractures with a radiofrequency-induced, highviscosity bone cement. Skeletal Radiol 43(4):493-498

18. (2011) DVO Guideline 2009 for prevention, diagnosis and therapy of osteoporosis in adults. Osteol 20(1):55-74

19. Andresen R, Radmer S, Lüdtke CW et al (2015) Conservative therapy versus $\mathrm{CT}$ guided balloon sacroplasty in the treatment of insufficiency fractures of the sacrum. Osteol (in press) (Article in German)

20. Kurth AA, Bayer-Helms H, Böwe C et al (2012) RadiofrequencyKyphoplasty-a novel vertebral augmentation system. A prospective, multi-center observational study. Osteol 21(3):174-179

21. Pflugmacher R, Bornemann R, Koch EM et al (2012) Comparison of clinical and radiological data in the treatment of patients with osteoporotic vertebral compression fractures using radiofrequency kyphoplasty or balloon kyphoplasty. Z Orthop Unfall 150(1):56-61

22. Smith DK, Dix JE (2006) Percutaneous sacroplasty: long axis injection technique. AJR Am J Roentgenol 186(5):1252-1255

23. Sciubba DM, Wolinsky JP, Than KD et al (2007) CT fluoroscopically guided percutaneous placement of transiliosacral rod for sacral insufficiency fracture: case report and technique. AJNR Am J Neuroradiol 28(8):1451-1454

24. Lüdtke CW, Kamusella P, Andresen R (2012) Pain management in pathologic sacrum fracture with $\mathrm{CT}$ guided balloon sacral vertebroplasty. Fortschr Röntgenstr 184(6):578-580 (Article in German)

25. Elgeti FA, Marnitz T, Kröncke TJ et al (2010) DFine radiofrequency kyphoplasty (RFK)-kyphoplasty with ultrahigh viscosity cement. Fortschr Röntgenstr 182(9):803-805 (Article in German) 